\section{Focus on psychiatry in France}

\author{
HÉLÈNE VERDOUX and JEAN TIGNOL
}

The aim of this paper is to give an overview of the various facets of psychiatry in France. The selection of topics discussed, as well as the views expressed in this paper, are our own, and some of them might not reflect the views of other French psychiatrists.

\section{ORGANISATION OF MENTAL HEALTH CARE}

The organisation of health care in general and of mental health care in particular is centralised at a national level under the control of the Ministry of Health. Within this ministry, the General Health Directorate (Direction Générale de la Santé, DGS) is in charge of public health and care, and chooses public health priorities. The Directorate for Hospitalisation and Organisation of Care (Direction de l'Hospitalisation et de l'Organisation des Soins, DHOS) is in charge of organising the care provided by health structures. Regional structures (Agences Régionales d'Hospitalisation) have recently been introduced to regulate and control the hospital health budget at a regional level, in accordance with priorities defined at a national level. Total health expenditure in 2000 was $9.5 \%$ of gross domestic product (GDP) (compared with $7 \%$ in the UK). Mental

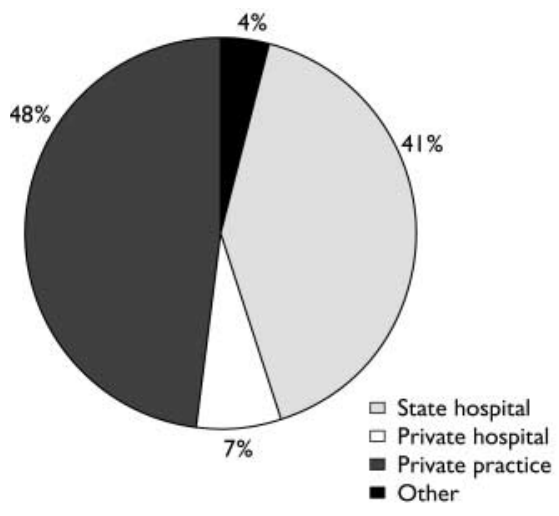

Fig. I Types of practice for French psychiatrists. disorders represent the second most costly diseases, accounting for $9.4 \%$ of total health expenditure, just after cardiovascular diseases $(10.7 \%)$ (Direction de la Recherche, des Etudes, de l'Evaluation et des Statistiques (DREES), 2002a).

\section{MENTAL HEALTH PROFESSIONALS}

The number of psychiatrists has grown considerably over recent decades. In February 2002 there were more than 13153 registered psychiatrists, of whom more than half $(52 \%)$ had a private practice or were working in private institutions (DREES 2001, 2002b) (Fig. 1). The ratio of psychiatrists to population $(23: 100000)$ is one of the highest in the world, just below Switzerland and the USA (Piel \& Roelandt, 2001). However, this abundance poorly reflects huge regional disparities (Fig. 2). As there is no legal regulation of the number of psychiatrists allowed to set up a private practice in a given area, psychiatrists are concentrated in the south of France and in the biggest cities (excluding the most deprived suburbs), with one in four private psychiatrists practising in inner Paris. By contrast, a large number of posts for psychiatrists in the state health system's hospitals (praticiens hospitaliers) lie vacant, especially in rural areas and in northern France. The grade of praticien hospitalier is obtained after passing a national examination. Successful candidates may apply for vacant posts anywhere in France and the selection of candidate for each post is decided by a national committee comprised mostly of administrators and representatives of professional unions. A decade ago,

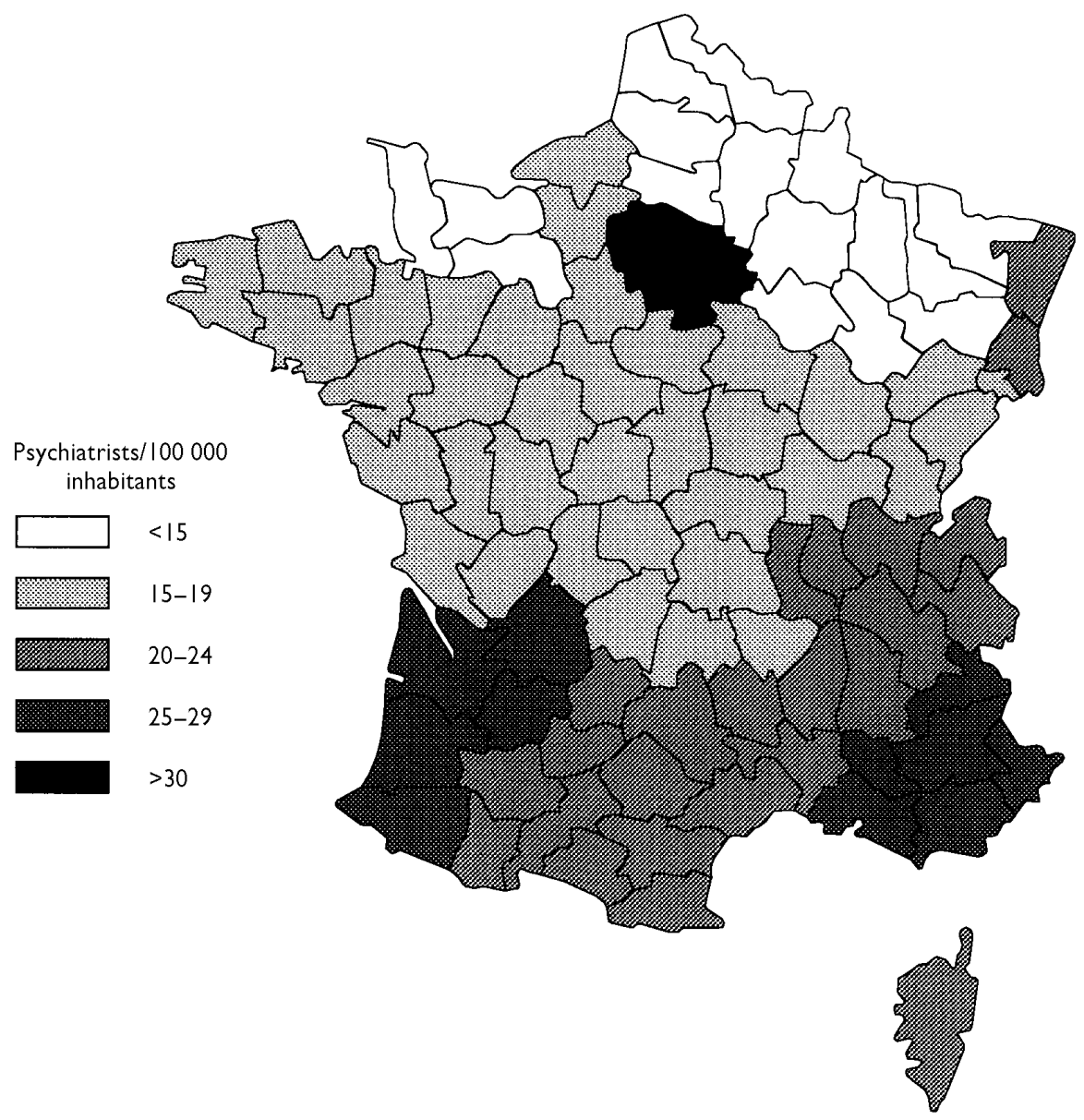

Fig. 2 Regional density for French psychiatrists. 


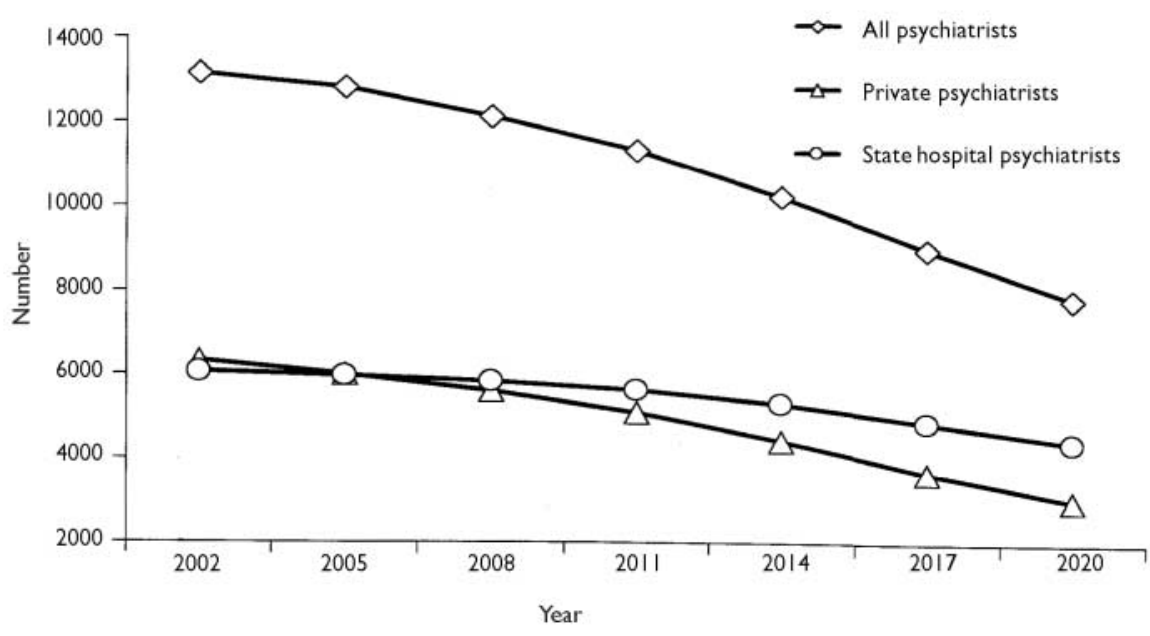

Fig. 3 Time-trend in the demography of French psychiatrists to 2020.

there were three candidates for each place; now this rate is close to one candidate for two places.

The mean age of French psychiatrists is 49 years, so a large number of psychiatrists will retire within the next 20 years. Owing to the drastic reduction since about 1980 in the number of medical students, and thus of psychiatric trainees, the number of psychiatrists should decrease by nearly $40 \%$ over the next two decades, to reach fewer than 8000 in 2020 (Fig. 3). This number will be comparable with that of most European countries, and should theoretically be sufficient to ensure France's mental health care needs (Piel \& Roelandt, 2001). However, geographical inequalities in access to psychiatric care will undoubtedly worsen if a new form of mental health care organisation is not decided in France, especially if health planners keep private psychiatry unregulated. Moreover, a large number of private psychiatrists are exclusively practising psychoanalytically oriented psychotherapy (Lafitte et al, 1996). To take into account demographic changes, a more reasonable organisation of mental health services would be that private psychiatrists delegate exclusive psychotherapy practice to other mental health professionals.

Of the 36000 French psychologists, 5000 are working in mental health institutions, mostly $(80 \%)$ in private ones. The number of psychologists in public mental health services should hopefully increase within the coming years. There are 51000 nurses and 6500 managerial staff members working in psychiatric institutions (Piel $\&$ Roelandt, 2001). The former diploma qualification of 'psychiatric nurse', which provided access to work restricted to psychiatric institutions, has recently been withdrawn and all newly trained nurses receive training in medical and surgical nursing also.

The title in France of 'psychotherapist' may be used, without official control, by clinicians and by people without university training in psychopathology. This lack of regulation may have deleterious consequences, as there are no guarantees regarding the quality of the training and the adequacy of the treatment offered by persons claiming to be psychotherapists. However, there is no consensus on whether a legal status of psychotherapist should be defined. A committee convened by the Minister of Health to make recommendations regarding the status of mental health professionals concluded that psychotherapists should have adequate university training, but was opposed to legal regulation of the title (Direction Générale de la Santé, 2002).

\section{PSYCHIATRIC HOSPITALS}

Psychiatric hospitalisations account for $15.5 \%$ of total hospital costs, the highest proportion for any illness (DREES, 2002a). In 1999, there were 65000 adult psychiatric in-patient beds and 27000 places for partial (day or night) hospitalisation. More than two-thirds $(68 \%)$ of the in-patient beds are in the state-run health service; of these, $70 \%$ are located in psychiatric hospitals, the other $30 \%$ being in general hospitals. The mean duration of stay was 32 days in 1999 (compared with 53 days in 1991). The reduction in the number of hospital beds started later in
France than in most other European countries, with the closure of one in five psychiatric beds between 1990 and 1997. As the mean number of beds in adult psychiatry per 1000 inhabitants was 1.08 in 1999, the objective of health planners that the ratio should be between 0.5 and 0.9 has not yet been reached, so further bed closures may be anticipated.

State hospital services are organised into 'sectors'. Each of the 829 adult psychiatry sectors is in charge of the mental health of a catchment area with a mean population of 72000 inhabitants. This organisation of mental health care, implemented in the 1960s, was based on public health principles such as the development of prevention and treatment in the community, and the guarantee that anyone living in France should have easy access to a mental health care facility and should be treated by an identified team (Reynaud $e t$ $a l, 1999 a)$. This organisation has been helpful in promoting access and continuity of care for people with severe mental disorders. However, the sector system has not totally fulfilled its promises, and it has led to some pernicious effects, at least in part because the ideological basis underlying this system has been applied in a rather rigid and static way, with limited attempts to adapt the system to social changes that have occurred over the past 30 years. There are huge disparities in staff and bed resources from one sector to another. For example, the actual catchment area population ranges from 20000 to 170000 and the numbers of psychiatrists and nurses range from 4 to 17 and 30 to 150 per 100000 inhabitants, respectively (DREES, $2002 c$ ). Each sector team is supposed to have the competence required to treat all types of mental health disorder occurring within the catchment area. This requirement that all psychiatric teams have equivalent and generic skills has dramatically limited the development of services specialised in the assessment and treatment of specific disorders.

Another limitation of the current organisation is that hospital-based care still occupies an overwhelming place, and community treatment is markedly underdeveloped (Piel \& Roelandt, 2001). In contrast with the huge cost of psychiatric hospitalisations, less than $10 \%$ of total mental health expenditure is used for community care (DREES, 2002a). The closure of beds over the past decade was mainly due to health cost reductions and it was 
not sufficiently coordinated with the transfer of staff to the community or with the development of sheltered housing for patients with the most severe disabilities. Thus, French psychiatric hospitals are now confronted with a problem well known in other European countries major difficulties in finding beds for acutely ill patients. Another problem of this hospital-based system is the fact that a large number of psychiatric hospitals built during the 19th century are located in rural areas outside the main cities. The lack of integration of psychiatric care in the community and the scarcity of psychiatric services in general hospitals, has been regularly criticised (Cour Des Comptes, 2000), particularly as it contributes to the stigmatisation of mental disorders (Piel \& Roelandt, 2001).

\section{COMPULSORY ADMISSIONS}

The proportion of compulsory psychiatric admissions was $13 \%$ in 1998 and it increased by $57 \%$ between 1988 and 1998 (Piel \& Roelandt, 2001), probably as a consequence of the change in the law in 1990. There are two types of compulsory admission (Goumilloux, 1991). That most frequently imposed (hospitalisation à la demande d'un tiers) is based on a medical decision and concerns persons with a mental state 'requiring urgent treatment and permanent medical supervision'. This hospitalisation is requested by a third party, that is by anyone who is concerned about the mental health of an individual, and its necessity has to be confirmed by two medical doctors. The second, hospitalisation d'office, is decided by a state administrator (préfet) for individuals 'threatening public order or the security of persons'. This decision has to be supported by a medical report justifying hospitalisation. The law does not govern the duration of compulsory admission, but a medical report confirming that hospitalisation is still required has to be provided after 24 hours, after 15 days and then monthly.

\section{ACCESS TO CARE}

The French health system has several strengths, especially the guarantee of universal access to care, free treatment for severely ill or socially disadvantaged persons, and (at least until now) access to the most appropriate treatment, regardless of cost (although treatments that are unnecessary or of questionable efficacy are being more and more regulated). Although a large number of patients are referred to psychiatrists by general practitioners (GPs), French patients have free access to private or public mental health professionals, which means that they can consult a specialist without a GP referral. In public mental health services, the rule of sectorisation does not - theoretically - apply to the patient, who can choose to be treated by a team other than the one in charge of the catchment area.

Psychiatric treatment provided by stateemployed mental health professionals is free of charge and available to everybody, and is funded by a state national health insurance. Private psychiatric treatment is part-funded by the national health insurance and the balance may be met by private insurance. If the patient has a chronic or severe mental illness, or is severely deprived, treatment provided by private psychiatrists is free (the psychiatrists' fees are paid in full by the state). The prescription of medication is regulated by national guidelines (Références Médicales Opposables), which are, in theory, constraining for prescribers. There is no limit to the number of psychiatric consultations (including the number of psychotherapy sessions) refunded from the national health insurance. The cost of psychoanalytic treatment by private psychoanalysts is not usually refunded, and that of psychotherapy provided by private psychologists is never refunded (although this situation may change in years to come).

\section{ORGANISATION OF CARE FOR SPECIFIC POPULATIONS}

\section{Child and adolescent psychiatry}

There are 323 sectors for child psychiatry, each of which governs a catchment area that encompasses roughly three adult psychiatry sectors, that is 250000 people. The official upper limit of age of patients treated by child and adolescent psychiatry sectors is $\mathbf{1 6}$ years. In accordance with the rule of generic competences underlying state psychiatric services, most sectors have no team specialised in adolescent mental health. The number of child and adolescent psychiatric beds is relatively low $(0.19$ beds per 1000 inhabitants), and a large number of sectors $(n=182)$ have no child and adolescent beds at all. The closure of child psychiatric beds that took place in the 1970s was not driven by the pressure of cutting costs. It was decided on by child psychiatrists who thought that the hospitalisation of children could be replaced by day hospitalisation and community psychiatry. A limitation of this organisation of child and adolescent psychiatric care is that young adolescents frequently have to be hospitalised in adult psychiatry wards. As improvement in health and access to care for adolescents is considered a national priority, this situation is slowly changing, with the introduction of mental health services and hospital wards for adolescents.

\section{Perinatal psychiatry}

In France perinatal psychiatry has developed mostly under the influence of child psychiatrists with a psychoanalytic background. Thus, therapy is focused mainly on mother-infant or father-infant interactions. There are a few mother and baby units (about 20) and most are managed by child psychiatrists (Sutter \& Bourgeois, 1998). This situation is slowly changing; some units are now managed by adult psychiatrists and are more focused on the treatment of the mother's mental illness.

\section{Old age psychiatry}

People older than 65 years represent $20 \%$ of patients treated by state psychiatric services (Reynaud et al, 1999a). There is no official sub-speciality of old age psychiatry, even if postgraduate training in geriatric care is available for psychiatrists (as well as for any GP or specialist). In accordance with the rules of generic competences for the sectors in psychiatry, most sectors have no specific teams and wards for geriatric patients. Nevertheless, some sectors have chosen to collaborate in the development of common structures for treating older people.

\section{Forensic psychiatry}

There are 26 sectors of forensic psychiatry (Services Médico-Psychologiques Régionaux, SMPR), functioning under the aegis of the Ministry of Health and located inside prisons, where they are in charge of inmates' mental health assessment and care. If the mental state of a prisoner is not compatible with the care being given inside prison, he or she can be referred to a psychiatric hospital, where he or she has the dual status of patient and prisoner. 
There are also four psychiatric units for 'difficult patients' (Unités pour Malades Difficiles, UMD); these are located inside psychiatric hospitals and have a total of 400 beds. These units are designed to treat violent and dangerous patients, and all admissions to them are compulsory. Patients may be referred after having been judged as not responsible for their criminal acts because of severe mental illness, they may be prisoners referred by the SMPR, or they may be referred by a psychiatric team because they are too dangerous to be treated in a standard psychiatric ward. There is no maximum legal duration of stay in a UMD, and the decision of discharge (from a prison or a hospital psychiatric ward) is taken on the advice of a medical committee.

A law passed on 17 June 1998 is aimed at preventing recidivism in sexual offenders by promoting medical treatment of their condition. According to this law, which has generated major controversy among psychiatrists, sexual offenders can be sentenced by judges to undertake medical treatment. The decision is taken after a medical assessment, and the judge nominates a 'coordinating doctor' in charge of organising the interactions between the legal authorities and the doctor treating the sentenced sexual offender. Medical confidentiality is thus protected. This complex and expensive new procedure is currently being introduced, and it requires the creation of a large number of medical posts.

\section{Substance misuse disorder}

Over recent years there has been considerable effort in France to promote a unified approach to substance misuse disorders through the new subspeciality of 'addictology'. Nevertheless, the systems of care for alcoholism and for drug addiction are still separate. Alcohol is an important health problem in France, but it is felt that services for people with alcohol-related problems are, on the whole, inefficient (Reynaud et al, 1999b). Services are mostly based in specialised out-patient centres offering consultations for alcohol disorders (Centres de Consultation Ambulatoire en Alcoologie, CCAA). These centres report 88000 clients a year, representing $2-4 \%$ of the estimated prevalence of people with alcohol-related problems. However, the entire French health care system is concerned about alcohol disorders: for instance, one in five adults presents to a GP with alcohol-related risk factors or disorders. Among in-patients, $18 \%$ have alcohol-related problems in general hospitals and $25 \%$ in psychiatric hospitals, and $20-25 \%$ of admissions to emergency facilities are related to alcohol misuse (Reynaud et al, 1999b). Only a minority of these health care settings have devised adequate protocols to treat alcohol disorders. Only a few specific in-patient units have been created in general hospitals, as well as liaison teams aimed at helping patients and hospital teams to cope with alcohol-related problems.

Although drug addiction is not as great a problem as alcohol misuse, it benefits from a care structure based on state law. It is entirely state-funded and free of charge to the patient. It is based mainly in Centres for the Specialised Care of Drug Addicts (Centres de Soins Specialisés pour Toxicomanes, CSST), which are out-patient units with a strong component of social workers. The 227 such centres reported 65000 clients in 1995 (Reynaud et al, 1999b). Since 1996, GPs have been able to prescribe buprenorphine for opiate addicts. There are currently an estimated 75000 opiate addicts in France taking buprenorphine, mainly prescribed by GPs, out of an estimated total of 150000 to 200000 opiate addicts (Observatoire Français des Drogues et Toxicomanies, 2002). The implementation of buprenorphine treatment by GPs has resulted in a dramatic reduction in overdose deaths and a considerable improvement in the health and quality of life of opiate addicts (Auriacombe et al, 2001). This could serve as a model for a first-line treatment of psychiatric disorders by GPs to make up for the foreseeable shortage in psychiatrists in the near future.

\section{Patients with psychiatric or learning disabilities}

Psychiatric institutions funded by the national health insurance are responsible for treating mental disorders, whereas social services funded by other state social agencies at a local level are responsible for managing disability resulting from psychiatric health problems. 'Medico-social institutions' have dual authority and are funded by both the national health insurance, social security and the state social agencies. There are 86000 places for adults in sheltered accommodation, including 11000 places in maisons d'accueil spécialisées (specialised sheltered housing) for patients with severely disabling mental illnesses. There are 125000 places (residential and day care) for children and adolescents, including 73000 places in institutions specialised in the education of children with learning disabilities (Piel \& Roelandt, 2001). The number of places in medico-social institutions for adults with severe mental disorders is markedly insufficient, and adults with autism or with psychosis with marked deficit are too frequently hospitalised for months and even years in psychiatric wards (even though the daily cost of sheltered accommodation is considerably lower than that of full-time hospitalisation). A general comment regarding the French mental health system is that the distinction between the social and the medical components of care is too often unclear, and the management of social problems is frequently delegated to medical institutions and professionals.

\section{PSYCHIATRIC TRAINING AND ACADEMIC PSYCHIATRY}

Training in psychiatry begins after 6 years of general medical studies. The choices of speciality and of university depend on performance in a national exam, the internat, which regulates access to all medical specialities. The number of internes posts in psychiatry at each university is regulated at a national level. In 2001, 176 posts were open in France. The duration of psychiatric training is 4 years, including at least 1 year in a child and adolescent psychiatric department and at least 6 months in a university department of psychiatry. Although most academic psychiatrists are against it, 1 year of training in non-psychiatric medical services may soon become compulsory, which would reduce the time spent in adult psychiatry to 2 years. At the end of the 4-year training period and the completion of a thesis on clinical or medical research, the title of 'medical doctor specialised in psychiatry' is awarded. There are only two official qualifications in subspecialities: adult psychiatry and child psychiatry. Education in psychiatry can be completed by a 1-year non-compulsory training in addiction, pharmacology or forensic medicine. Theoretical teaching on psychotherapeutic methods is provided in most universities.

Professors of psychiatry are responsible for organising teaching in psychiatry for 
medical students and training in psychiatry for interns. The title of professor is awarded after a yearly national examination. The curricula vitae and academic skills of candidates selected by the universities are examined by two national juries of professors, of adult psychiatry and of child psychiatry, respectively. Candidates who pass the examination can apply for a post at the university of their choice. All professors of psychiatry have academic (halftime) and hospital (half-time) positions, most of them also being heads of psychiatric departments. In 2002 there were 57 professors of adult psychiatry and 32 professors of child psychiatry for 13153 psychiatrists (compared with 97 professors of neurology for 1680 neurologists), with a gender ratio close to one female professor to 10 males. A full professorship is one of very few permanent academic positions, and this drastically restricts the opportunity for psychiatrists interested in teaching and/ or research to find a position giving them the possibility of remaining involved in such activities. The position of chef de clinique (assistant professor) is a temporary one, with a duration restricted to 4 years.

\section{RESEARCH}

Psychiatric research leading to publication in scientific journals with an international audience is markedly underdeveloped in France compared with most other European Union countries (Takei \& Verdoux, 1997). Of the 350 research units funded by the National Institute of Health and Medical Research (Institut National de la Santé et de la Recherche Médicale, INSERM), four are specifically devoted to psychiatric research, and in 2001 the budget for psychiatric research was only $2.5 \%$ of the total INSERM budget (see http://www.inserm.fr). The number of research units involved in psychiatric research founded by the National Centre for Scientific Research (Centre National de la Recherche Scientifi$q u e, \mathrm{CNRS})$ is also remarkably low. The scarcity of academic posts in psychiatry and the lack of full-time academic positions are also undoubtedly detrimental to the development of research. Although a large number of non-academic psychiatrists are interested in research, the lack of training and/or time is limiting their involvement in research projects. The overwhelming predominance of the psychoanalytic model in the training and in the practice of psychiatrists for more than three decades (van Os et al, 1993) has probably contributed to slowing down the development of empirical clinical research.

Promising signs suggest that improving psychiatric research is now considered to be a national priority by the psychiatric community as well as by the national research agencies. An INSERM committee (intercommission) on mental health and psychiatric disorders was created in 2000 to recruit researchers in psychiatry and to assess applications for the creation of INSERM research units devoted to psychiatry. In 2002, a task force on the physiopathology of mental disorder was created by INSERM to promote research training and generate research projects. Applications for psychiatric research projects to the national programme for hospital research grants (Programmes Hospitaliers de Recherche Clinique) have been regularly encouraged in recent years. The Minister of Health is promoting several research grant programmes, through the Mission Interministérielle de Lutte contre la Drogue et la Toxicomanie (MILT) (for research into substance misuse disorders) and through the Mission Recherche (MiRe) mental health research programme, co-funded by INSERM and CNRS (for research into the social aspects of mental disorders). There are very few private sources of funding, with the exception of the Fondation pour la Recherche Médicale (FRM), a charity that has recently developed research grant programmes for psychiatric research, especially on autism. More and more young psychiatrists and psychologists are being trained in research, and a growing number of research groups now produce research of high scientific quality. However, several years of intensive support will probably be required to improve the backward state of French psychiatric research. This progress will be highly dependent on whether or not the French Government over the coming years considers research in general, and psychiatric research in particular, as a national priority.

\section{PSYCHIATRIC ASSOCIATIONS}

The exact number of scientific and professional psychiatric associations in France is difficult to establish, owing to their high number, the constant appearance of new ones and the frequent schisms in some psychoanalytical groups. There is no French equivalent of the Royal College of Psychiatrists: the only legal obligation for psychiatrists (and for all French medical practitioners) is to register and to pay yearly fees to the Conseil de l'Ordre des Médecins, an elected national medical agency set up during the Second World War to regulate and control medical activity. A decade ago, no single organisation represented French psychiatrists, so the Government promoted the creation of the French Federation of Psychiatry (Fédération Française de Psychiatrie, FFP), aimed at gathering together the numerous existing professional associations, which are free to become members of the FFP if they wish.

Associations representing users and families have experienced encouraging improvements in their position and impact within the organisation of mental health care over recent decades. They actively support the development of community care, members of users' associations are part of hospital managerial boards and hospital committees on patients' rights, and are involved in the planning of new hospital projects. They also participate in national consensus conferences aimed at establishing guidelines for psychiatric treatment, in the INSERM task force on psychiatry, in the INSERM expert board on the assessment of psychotherapy treatments, and in the MiRe-INSERM-CNRS mental health research programme. Users' associations have recently published a report proposing recommendations for improvement of mental health care (Union Nationale des Amis et Familles de Malades Mentaux, 2002). They are very active in promoting the development of community psychiatry, and one of their main targets is to convince the national agencies to reduce the huge shortage of 'medico-social' and sheltered accommodation. The Union Nationale des Amis et Familles de Malades Mentaux (UNAFAM) primarily represents the interests of the families and friends of people with mental illnesses, whereas the Fédération Nationale des Associations (d'(ex-) Patients Psychiatriques (FNA-Psy) mostly represents former and current psychiatric patients.

\section{THE FUTURE}

Following on from several national programmes aimed at renovating French mental health structures (Provost \& Bauer, 2001), in 2001 the then Minister of Health 
proposed a new initiative entitled 'Mental Health: the user at the core of an organisation in need of renovation' ('Santé Mentale: l'usager au centre d'un dispositif à rénover'), the aim of which is to place the service user at the centre of a remodelled health care system. The major themes outlined in this programme clearly point to the weaknesses of contemporary French psychiatry: promoting campaigns against stigma; reinforcement of patients' rights by active support of users' associations; improvement of professional practice (geographical regulation of the demographic distribution of psychiatrists; recruitment of psychologists; development of networks with legal, social and educational services); and the development of preventive programmes (especially for suicide, depression and problems specific to adolescents and individuals who are socially disadvantaged), social rehabilitation, community psychiatry and psychiatric research. Although some of the programme's recommendations have generated wide debate in the psychiatric community, its obvious intention to make improvement in mental health services a national public health priority is welcomed. It is to be hoped that its worthy propositions are followed by actual changes.

\section{ACKNOWLEDGEMENTS}

The authors thank the following for providing information and for commenting on an earlier version of this manuscript: Jacqueline Delbecq, Directeur de recherche INSERM, Director of the MiRe Mental Health programme and in charge of research issues at UNAFAM; Professor Marc Auriacombe; Dr
Bernard Antoniol, Florent Cochez, Régis Goumilloux and Anne-Laure Sutter, psychiatrists, Hôpital Charles Perrens, Bordeaux; and Professor Bernard Bégaud, Department of Pharmacology, President of the University Victor Segalen Bordeaux 2. We also thank Ray Cooke, who supervised the English of this paper.

\section{REFERENCES}

Auriacombe, M., Franques, P. \& Tignol, J. (200I)

Deaths attributable to methadone vs buprenorphine in France. JAMA, 285, 45

Cour Des Comptes (2000) Rapport au Président de la République. L'Organisation des Soins Psychiatriques. Paris: Cour Des Comptes.

Direction de la Recherche, des Etudes, de I'Evaluation et des Statistiques (200I) Les médecins, Estimations au I janvier 200I. Série Statistiques no. 28. DREES. http://www.sante.gouv.fr/drees/seriestat/pdf/ seriestat28.pdf

- (2002a) Des Comptes de la Santé par Pathologie. Un Prototype sur l'Année 1998. Etudes et Résultats no. 188. DREES. http: / /www.sante.gouv.fr/drees/etuderesultat/er-pdf/erl88.pdf

- (2002b) Projections Medecins 2002-2020. Série Statistiques no. 30. DREES. http: / /www.sante.gouv.fr/ publication. htm

- (2002c) Une Typologie des Secteurs de Psychiatrie Générale en 1999. Etudes et Résultats no. 163. DREES.

Direction Générale de la Santé (2002) L'évolution des Métiers en Santé Mentale: Recommandations Relatives aux Modalités de Prise en Charge de la Souffrance Psychique jusqu'au Trouble Mental Caractérisé. DGS, Ministère de l'Emploi et de la Solidarité.

Goumilloux, R. (199I) Législation Psychiatrique. Paris: Masson.

Lafitte, C., Martin, C., Grabot, D., et al (1996) A survey of private practice psychiatrist's training and activity in Aquitaine, France, in 1993. Encephale, 22 417-421.

Observatoire Français des Drogues et

Toxicomanies (2002) Drogues et Toxicomanies.
Indicateurs et Tendances. Paris: Observatoire Français des Drogues et Toxicomanies.

Piel, E. \& Roelandt, J. (200I) Rapport de Misson. De la Psychiatrie à la Santé Mentale. Ministère de l'Emploi et de la Solidarité, Ministère Délégué à la Santé.

Provost, D. \& Bauer, A. (200I) Trends and developments in public psychiatry in France since 1975. Acta Psychiatrica Scandinavica, 104 (suppl. 410), 63-68.

Reynaud, M., Gallot, A. \& Lefèvre, L. (1999a) La politique de santé mentale en France. In Psychiatrie Années 2000. Organisations, Evaluations, Accréditation (eds V. Kovess, A. Lopez, J. Pénochet, et al), pp. 3-24. Paris: Flammarion Médecine-Sciences.

_, Parquet, P. \& Lagrue, G. (1999b) Les Pratiques Addictives Usage, Usage Nocif et Dépendance aux Substances Psychoactives. Paris: Direction Générale de la Santé, Secrétariat d'Etat à la Santé et aux Affaires Sociales.

Sutter, A. \& Bourgeois, M. (1998) Unités mère-enfant en psychiatrie périnatale. In Encyclopédie Médico-Chirurgicale, vol. 37, pp. 204-210. Paris: Elsevier.

Takei, N. \& Verdoux, H. (1997) Research activities on schizophrenia in 17 non-English speaking countries: a Medline survey. European Psychiatry, 12, 319-320.

Union Nationale des Amis et Familles de Malades Mentaux (2002) Le Livre Blanc des Partenaires de lo Santé Mentale en France. Paris: Editions de Santé.

Van Os, J., Galdos, P., Lewis, G., et al (1993) Schizophrenia sans frontières: concepts of schizophrenia among French and British psychiatrists. BM/, 307, 489-492.

Hélène Verdoux Université Victor Segalen Bordeaux 2, and University Department of Psychiatry, Hôpital Charles Perrens, I2I rue de la Béchade, 33076 Bordeaux Cedex, France. Tel: (33) 55656 I7 32; fax (33) 5565635 46; e-mail: helene.verdoux@ipso.u-bordeaux2.fr

JeanTignol Université Victor Segalen Bordeaux 2, and University Department of Psychiatry, Hôpital Charles Perrens, Bordeaux, France 